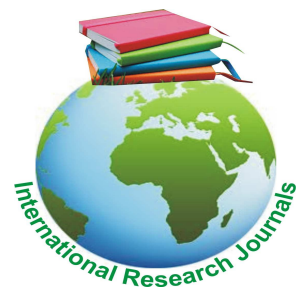

Journal of Medicine and Medical Sciences Vol. 8(6) pp. 084-087, October 2017

DOI: http:/dx.doi.org/10.14303/jmms.2017.183

Available online http://www.interesjournals.org/JMMS

Copyright (C) 2017 International Research Journals

Case Report and Review

\title{
Valsava Retinopathy: A review
}

\author{
${ }^{\star}$ Bassey Fiebai ${ }^{1}$, Efeoghene U Ani ${ }^{2}$, Datonjo A George ${ }^{1}$ \\ ${ }^{1}$ Department of Ophthalmology, University of Port Harcourt Teaching Hospital, Port Harcourt, Nigeria. \\ ${ }^{2}$ The Ophthalmic Specialists Eye Hospital, Port Harcourt, Nigeria \\ *Corresponding author's email: bassief@yahoo.com
}

\begin{abstract}
The study was carried out to investigate the causes, presentation and management of premacular hemorrhage secondary to Valsava retinopathy in Port Harcourt. Case folders of patients who presented to the retina units of the University of Port Harcourt Teaching Hospital and a private hospital between 2014 and 2016, were reviewed. Data collected includes age, sex, presenting visual acuity, risk factors, and treatment modalities. Three eyes of two patients were reviewed. One patient had bilateral premacular haemorrhage. Both patients had a very significant improvement, with best corrected acuity of 6/6 within three weeks of conservative management involving sleeping in standard Fowlers position. Valsava retinopathy though a rare condition can cause a profound loss of vision. Spontaneous recovery with full visual function is common without intervention.
\end{abstract}

Keywords: Valsava Retinopathy, Premacular haemorrhage, Sudden loss of vision, Conservative management.

\section{INTRODUCTION}

Valsava retinopathy is a retinal pathology which is preretinal and hemorrhagic in nature. It occurs secondary to an increase in intra-thoracic or intra-abdominal pressure against a closed glottis and was first described by Duane (Duane, 1972).

A sudden increase in intra-thoracic pressure causes diminished venous return to the right side of the heart. This in turn lowers the mean arterial pressure, causing a reflex tachycardia and peripheral vasoconstriction. Also, the release of the strain leads to a prompt reduction in intra-thoracic pressure also lowering the blood pressure and increasing cardiac flow (Chandra et al., 2005; Saricaoglu et al., 2009). Blood pressure increases in the peripheral parts of the body during a Valsava maneuver. Spontaneous rupture of the retinal capillaries results from increase in intraocular venous pressure.

It is commonly found in young adults after strenuous activity. Causes of Valsava retinopathy reported include vigorous sexual activity, vomiting, trauma, weight lifting, straining on defecation and labour (Ahmad et al., 2009; Fernadez, 2012). It has also been reported in sickle cell disease (Konotey-Ahulu, 1997). Patients complain of a dramatic sudden loss of central vision, sometimes associated with floaters. Bleeding gets absorbed spontaneously after several weeks and months with good return of vision. However, there may be some visual impairment as a result of toxic damage to the retina from prolonged contact with the iron and hemoglobin, pigmentary changes and epiretinal membrane formation (De Maeyer et al., 2007). Lamellar macular hole has also been reported as a sequel of Valsava retinopathy (Zheng-gao, 2014).

Treatment modalities reported include conservative management especially for small premacular hemorrhages less than 1 disc diameters (DD), neodymium yttrium aluminium garnet laser (Nd-YAG) or Green laser posterior hyaloidotomy, pars plana vitrectomy and pneumatic displacement of the haemorrhage with an intravitreal gas with or without recombinant tissue plasminogen activator (Ahmad, 2009; Fernandez, 2012; Conway et al., 1999).

These modalities of treatment come with their attendant risks especially in the inexperienced hands. Conservative management with appropriate posturing may still achieve rapid spontaneous resolution with full recovery.

\section{MATERIAL AND METHODS}

A review of cases of premacular haemorrhage secondary 
Fiebai et al., 085

Table 1: Patients baseline data and final examination

\begin{tabular}{|l|l|l|l|l|l|l|l|}
\hline Patient & Age/Sex & Aetiology & Eye & $\begin{array}{l}\text { Initial } \\
\text { BCVA }\end{array}$ & Treatment & $\begin{array}{l}\text { Final } \\
\text { BCVA }\end{array}$ & $\begin{array}{l}\text { Duration of } \\
\text { resorption }\end{array}$ \\
\hline 1 & $34 / \mathrm{F}$ & Constipation & Lt & HM & $\begin{array}{l}\text { Observation/ } \\
\text { sleeping at Fowlers } \\
\text { position }\end{array}$ & $6 / 6$ & 3 weeks \\
\hline 2A & $16 / \mathrm{F}$ & $\begin{array}{l}\text { Sickle cell } \\
\text { trait }\end{array}$ & Rt & CF & $\begin{array}{l}\text { Observation/sleeping } \\
\text { at Fowlers position }\end{array}$ & $6 / 6$ & 3 weeks \\
\hline 2B & $16 / \mathrm{F}$ & $\begin{array}{l}\text { Sickle cell } \\
\text { trait }\end{array}$ & Lt & $6 / 36$ & $\begin{array}{l}\text { Observation/sleeping } \\
\text { at Fowlers position }\end{array}$ & $6 / 6$ & 3 weeks \\
\hline
\end{tabular}

KEY

Rt- Right eye

Lt- Left eye

$2 A$ - Second patient's right eye

2B-Second patient's left eye

BCVA- Best corrected visual acuity

CF - Counting fingers

HM- Hand movement

to Valsava retinopathy seen in the retina clinic of the University of Port Harcourt Teaching Hospital and a private clinic between 2014 and 2016. Case folders of the only 2 patients were reviewed. Data collected were age, sex, presenting visual acuity, risk factor, and treatment modality management. All the patients were followed up for at least 12 months.

\section{RESULTS}

Individual data of 3 eyes of 2 patients are presented in Table 1 above.

\section{DISCUSSION}

The first case in this series was that of a 34 year old woman. Who presented with a history of sudden loss of vision of one day's duration. The only positive history was chronic straining on stooling. Presenting visual acuity was 'Hand movement', see table 1. Fundus examination revealed an extensive preretinal haemorrhage involving the macular greater than 10 disc diameters (Figure 1).

The second was a case of bilateral spontaneous premacular haemorrhage in a patient with a sickle cell trait (AS). Patient had been recently treated for severe malaria and had received blood transfusion. Visual acuity in the Right eye was 'Counting fingers and Lt Eye 6/36, see table 1 .

Examination of both fundi revealed premacular hemorrhages within 2-3 disc diameters and other preretinal haemorrages in the superior and inferior retina (Figure 1). Both patients in this review where advised to sleep in a standard Fowler's position (45-60 degrees head up). Both patients had spontaneous visual recovery after 3 weeks.

Conservative management of premacular hemorrhages has been advocated for haemorrages less than 1-3 disc diameters (Ahmad et al., 2009; Fernadez, 2012). These studies have recommended intervention for hemorrhages greater than 1-3 disc diameters, dense hemorrhages, and hemorrhages which do not resolve spontaneously (Ahmad et al., 2009; Fernadez, 2012).

In our series, one of the patients with a hemorrhage of 10 disc diameters achieved full spontaneous resolution in 3 weeks. The studies cited above did not categorically mention what the conservative management entailed. Rennie et al. reported a slow resolution of 3-6 months in 2 of the 4 patients managed conservatively in their series (Rennie, 2001). We believe that nursing the patient at 45 degrees contributed significantly to the gravitation of the premacular hemorrhage and rapid resolution in the 2 patients in our review. 
086 J. Med. Med. Sci.

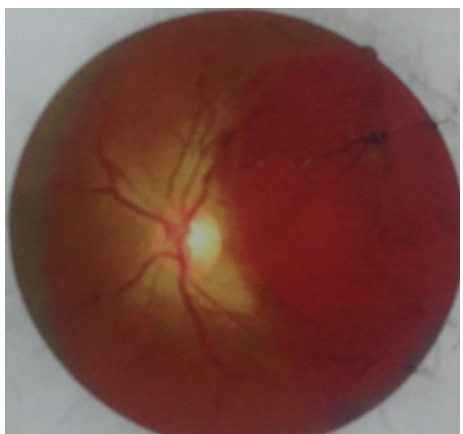

Patient 1 at presentation

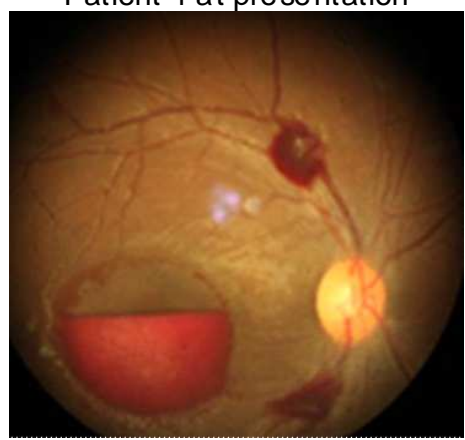

Patient 2 at presentation- Rt eye

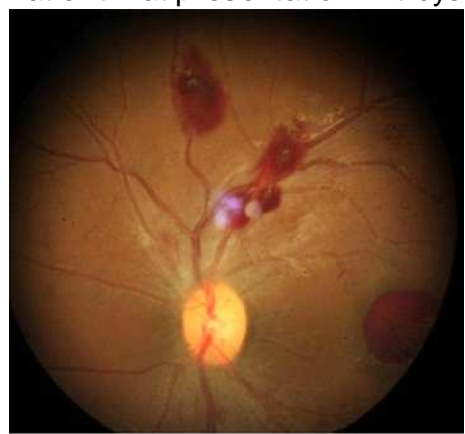

Patient 2 at presentation- Lt eye

Figure 1: Fundus pictures of 3 eyes

\section{CONCLUSION}

Conservative management of valsava retinopathy involving appropriate posturing of the patient still achieves the desired spontaneous resolution with full recovery, eliminating the risks associated with other modalities of intervention.

\section{REFERENCES}

Ahmad Abadi M, Karkhaneh R, Mirshahi A, Lashay A, Harandi Z, Roohipoor R, Esfahani MR, Tabatabaee SA, Movassat $M$, Ghassemi $F$ (2009). Premacular hemorrahge in Valsava retinopathy: A study of 21 cases. Iran. J. Ophthalmol. 21:11-16.

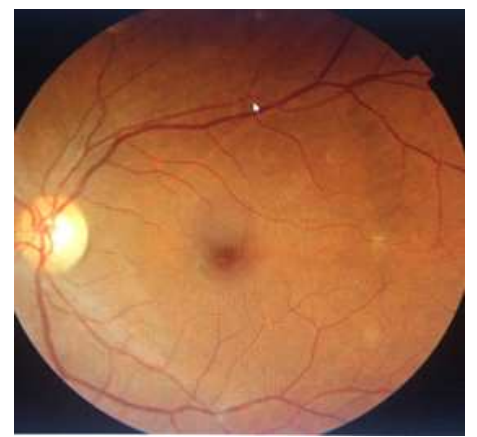

Patient 1 after 3 weeks

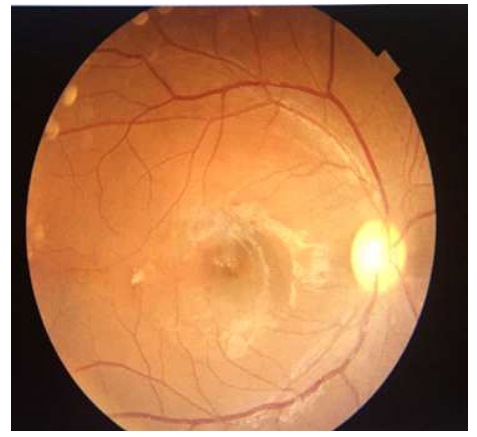

Patient 2 after 3 weeks- Rt eye

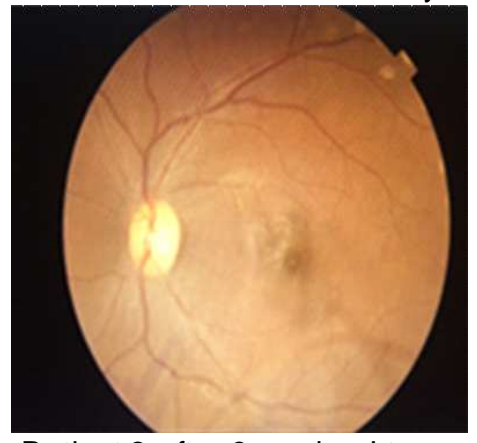

Patient 2 after 3 weeks- Lt eye

Chandra P, Azad R, Pal N (2005). Valsalva and Purtscher's retinopathy with optic neuropathy in compressive thoracic injury. Eye. 19:914-915.

Conway MD, Peyman GA, Recasens M.(1999) Intravitreal tPA and SF6 promote clearing of premacular subhyaloid hemorrhages in shaken and battered baby syndrome. Ophthalmic Surg. Lasers. 30: 435-41.

De Maeyer K, Van Ginderdeuren R, Postelmans L, Stalmans P, Van Calster J (2007) Sub $\square$ inner limiting membrane haemorrhage: causes and treatment with vitrectomy. $\mathrm{Br}$. J. Ophthalmol. 91: 869-872.

Duane TD (1972). Valsalva hemorrhagic retinopathy. Trans. Am. Ophthalmol. Soc. 70:298-313.

Fernandez MG (2012). Long term evolution of valsava retinopathy; A case series. J. Med. Case reports. 6:346.

Konotey-Ahulu F (1997). Valsalva vitreous haemorrhage and retinopathy in sickle cell haemoglobin $\mathrm{C}$ disease. Lancet. 
Fiebai et al., 087

349:1774.

Rennie CA, Newman DK, Snead MP, Flanagan DW (2001) $\mathrm{Nd}$ YYA laser treatment for premacular subhyaloid hemorrhage. Eye. 15:519-524.

Saricaoglu MS, Kalayci D, Guven D, Karakurt A, Hasiripi H (2009). Decompression retinopathy and possible risk factors. Acta Ophthalmol. 87:94-95.
Zheng-gao Xie, Su-qin Yu, Xi Chen, Jun ZhuFang Chen (2014). Macular hole secondary to Valsalva retinopathy after doing push-up exercise. BMC Ophthalmol. 14:98 